\title{
Gabapentin Withdrawal Syndrome: A Diagnostic Conundrum
}

\author{
Keta Thakkar ${ }^{1}$ Georgene Singh ${ }^{1}$ Shalini Nair ${ }^{2}$ Krishna Prabhu ${ }^{3}$
}

${ }^{1}$ Department of Neuroanaesthesia, Christian Medical College, Vellore, Tamil Nadu, India

2Department of Neurological Sciences, Christian Medical College, Vellore, Tamil Nadu, India

${ }^{3}$ Department of Neurosurgery, Christian Medical College, Vellore, Tamil Nadu, India

J Neuroanaesthesiol Crit Care 2022;9:62-63.

We report a case of a 56-year-old gentleman who presented with symptoms suggestive of trigeminal neuralgia with severe pain below the left lower premolars and molars for 2 years, which was aggravated while chewing food, brushing teeth, exposure to cold water, and associated with decreased sensation on the left side of the face. T2-weighted MRI driven equilibrium radiofrequency reset pulse (DRIVE) sequence confirmed the diagnosis, with vascular loop arising from the superior cerebellar artery, abutting the trigeminal nerve. He was initiated on tablet gabapentin $300 \mathrm{mg}$ thrice daily, tablet carbamazepine $500 \mathrm{mg}$ twice daily, and tablet pregabalin $25 \mathrm{mg}$ once a day at night, which failed to provide symptomatic relief, and was planned for retromastoid suboccipital craniotomy and microvascular decompression (MVD). The patient did not have any psychiatric illness or history of substance or drug abuse.

Preoperatively, his medications were continued in a timely manner with no additional premedication. Inside the operating room, after establishing the American Society of Anesthesiologists (ASA) standard monitors and insertion of intravascular access, anesthesia was induced with fentanyl, propofol, and vecuronium and intubated with an appropriately sized endotracheal tube. Anesthesia was maintained with propofol, fentanyl, vecuronium, and sevoflurane. The surgery was uneventful.

Extubation of the trachea was done, and the patient was shifted to the ICU for further monitoring. After an hour, he complained of severe unilateral headache beyond the site of surgery and palpitations. On examination, he was irritable and sweating profusely with a heart rate of 112 beats per minute (BPM), blood pressure of $180 / 90 \mathrm{~mm} \mathrm{Hg}$, and tachypneic at a rate of $22 /$ minute. Adequate analgesia was ensured, which failed to relieve the symptoms. Serum electrolytes, blood sugar, oral temperature, and acid-base status

published online October 24, 2021
DOI https://doi.org/

$10.1055 / \mathrm{s}-0041-1732832$ ISSN 2348-0548
Address for correspondence Georgene Singh, MD, DNB, DM, Department of Neuroanaesthesia, Christian Medical College, Vellore 632004, Tamil Nadu, India (e-mail: georgenesingh@ gmail.com).

were normal. Postoperative CT scan, 12-lead electrocardiogram, and cardiac markers were also within normal limits. Cholinergic crisis was ruled out. Brainstem edema, a rare complication after the MVD, was not considered, as there was neither a vascular compromise nor a pial breach. A review of the medication records revealed omission of morning and afternoon doses of tablet gabapentin $300 \mathrm{mg}$, leading to a drug-free interval of 18 hours. Tablet carbamazepine and tablet pregabalin were administered according to schedule. Gabapentin was immediately restarted orally. On reassessment, after 3 hours, he had a significant improvement in symptoms and vital signs were normal.

Gabapentin is a structural analog of the neurotransmitter $\gamma$-aminobutyric acid, which exerts a neuronal inhibitory effect by blocking voltage-dependent calcium channels. ${ }^{1}$ It is used extensively in neurosurgical patients for its analgesic and anticonvulsive properties. Gabapentin withdrawal has been previously reported within 12 hours to 7 days after stopping the drug as the serum half-life is 5 to 7 hours, although this is the first to be reported in a postoperative patient. ${ }^{2}$ The withdrawal symptoms resemble benzodiazepine or alcohol withdrawal due to the same mechanism of action and mainly include agitation, anxiety, irritability, palpitation, diaphoresis, nonspecific gastrointestinal symptoms, tachycardia, tachypnea, and hypertension. ${ }^{3.4}$ In severe cases, the withdrawal can also masquerade as seizures and catatonia, assuming significance in the differential diagnosis of a postoperative neurosurgical patient. ${ }^{5}$ In a patient post-MVD, this may mimic cardiac changes. Timely administration of the drug in the perioperative period, if need be with insertion of the nasogastric tube should be done, as parenteral preparation is not available for use. Abrupt discontinuation of gabapentin perioperatively in a patient with chronic intake should be prevented to avoid a gabapentin withdrawal
(C) 2021. Indian Society of Neuroanaesthesiology and Critical Care. All rights reserved.

This is an open access article published by Thieme under the terms of the Creative Commons Attribution-NonDerivative-NonCommercial-License, permitting copying and reproduction so long as the original work is given appropriate credit. Contents may not be used for commercial purposes, or adapted, remixed, transformed or built upon. (https://creativecommons.org/licenses/by-nc-nd/4.0/).

Thieme Medical and Scientific Publishers Pvt. Ltd. A-12, 2nd Floor, Sector 2, Noida-201301 UP, India 
syndrome. The gabapentin tapering can be adopted, especially for patients taking large doses, over a minimum period of 1 week, with a decrease of $100 \mathrm{mg}$ BD per day. Vigilance is advised during this period, as the gabapentin withdrawal can occur even during a taper. ${ }^{4}$

\section{Conflict of Interest}

None declared.

\section{References}

1 Kong VKF, Irwin MG. Gabapentin: a multimodal perioperative drug. ? Br J Anaesth 2007;99(6):775-786
2 Mersfelder TL, Nichols WH. Gabapentin: abuse, dependence, and withdrawal. Ann Pharmacother 2016;50(3):229-233

3 Norton JW. Gabapentin withdrawal syndrome. Clin Neuropharmacol 2001;24(4):245-246

4 Tran KT, Hranicky D, Lark T, Jacob Nj. Gabapentin withdrawal syndrome in the presence of a taper. Bipolar Disord 2005;7(3):302-304

5 Barrueto F Jr, Green J, Howland MA, Hoffman RS, Nelson LS. Gabapentin withdrawal presenting as status epilepticus. J Toxicol Clin Toxicol 2002;40(7):925-928 